DOI: $10.20287 /$ doc.d19.ac3

\title{
Gipsofila e a genealogia de um gesto
}

\author{
Luís Mendonça*
}

Gipsofila (Portugal, 2015, 61')

Realização e Produção: Margarida Leitão

Montagem: João Braz e Margarida Leitão

Gipsofila é um objeto estranho tanto na obra de Margarida Leitão como no quadro geral do que, por comodidade e sem problematizar em demasia, chamaria aqui de "cinema português". Este filme-oásis aparece devido a um conjunto de circunstâncias especiais. Desde logo, ele foi gerado em sede de dissertação de mestrado na Escola Superior de Teatro e Cinema, ou seja, é fruto de um contexto de liberdade, no pensamento e na ação, que seria porventura problemático no seio de um sistema de financiamento do cinema altamente regulamentado e esteticamente ortodoxo.

As raízes deste projeto remetem para um cinema do "eu" pouco presentes na tradição académica e estilística do cinema português que, baseado no primado clássico da mise-en-scène, se revela pouco atreito a semelhantes espaços de experimentação conceptual. Que Gipsofila surja como um filme-tese serve já de pista quanto à singularidade da posição que ocupa não só numa obra individual dividida entre a ficção atmosférica e o documentário observacional típico como, em plano geral, dentro da ideologia dominante do que se poderia denominar de cinema português.

Se quisermos fazer uma genealogia do gesto por trás de Gipsofila, facilmente iremos ter a um dos "géneros" mais emblemáticos do movimento avantgarde que marcaram os anos 50 e 60: o cine-diário. Jonas Mekas será a figura de proa do New American Cinema (NAC) e a ele se deve o aprimoramento de um cinema pessoal, sincero, inocente e aberto, onde o protagonista é o próprio cineasta, nas suas vivências e memórias (Mekas, 1960: 16). O cartão de um dos seus filmes, As I was moving ahead occasionally I saw brief glimpses of beauty, traduz bem o alcance estético e ético deste cinema: "A film where nothing happens". Ouvimos em over durante um fluxo ininterrupto de imagens caseiras filmadas por Mekas ao longo da sua vida: "If nothing happens, let's

* Doutorando. Universidade Nova de Lisboa, Faculdade de Ciências Sociais e Humanas, Programa de Doutoramento em Ciências da Comunicação. Bolseiro FCT Fundação para a Ciência e a Tecnologia. 1099-085, Lisboa, Portugal. 
continue, anyway. That's how life is". Estas mesmas palavras poderiam servir de comentário ao que se passa - e ao que passa - na obra de Margarida Leitão.

Por outro lado, Gipsofila é e não é como os filmes de Andy Warhol, a outra figura incontornável do NAC. É, porque neles o tempo é o principal protagonista. Não é, porque o principal protagonista, o tempo, é sempre veículo de uma subjetividade, do "eu" da cineasta que nos faz entrar, sem cartas na manga, no seu dia-a-dia. Contudo, se Andy Warhol trabalha a noção de duração, ou de "tempo sólido", como lhe chama Parker Tyler (1995: 36), sobretudo em filmes como Eat, Blowjob, Sleep e Empire, Mekas trabalha a ideia de fluxo, sendo os seus filmes como uma corrente incessante de imagens, qual hemorragia mnésica do "eu". Dito de outra maneira: Warhol privilegia o tempo vertical no plano, ao passo que Mekas será sobretudo um cineasta do tempo horizontal na montagem.

Como podemos situar aqui o gesto de Margarida Leitão? Algures a meio, transformando Mekas numa postura estética e ética que se materializa num modelo formal mais próximo de Warhol. Ainda em As I was moving ahead..., ouvimos em over: "Making you watch these very personal, insignificant moments of my life... We all look for something more important (...). At some point we realize that one day follows another and things we felt were so important yesterday (...) we have forgotten them today. Life is continuum". Em Gipsofila a vida, no seu continuum não-significante, é o grande acontecimento, mas para capturar o tempo como acontecimento Margarida Leitão privilegia o quadro (a duração) ao invés da montagem (o fluxo). O tempo partilhado por neta e avó, a própria cineasta e a sua avó Lourdes Albuquerque, vai-se solidificando num dispositivo formado por longos planos que se colam entre si como se fossem "blocos" de realidade mutuamente autónomos, para usar uma expressão de Bazin (1992: 370), que seria depois retomada por Gilles Deleuze. Fica-se mesmo com a sensação de que a ordem dos "episódios" - para não dizer "cenas" - é esta, mas podia ser outra.

O principal acontecimento (verdadeiro happening) em Gipsofila é a partilha de um tempo, ou melhor, de uma duração entre duas pessoas sob o mesmo teto. O que passa aqui - e faz respirar o filme e aliviar a sensação de cativeiro que ele encerra - é essa duração posta em partilha entre neta e avó nas divisões do apartamento desta última. A ligação a Warhol é assumida no próprio filme quando Margarida Leitão aparece a dormir a sesta com a avó. A avó acorda e pergunta à neta qual o interesse de filmar aquilo. Ela responde-lhe docemente: "Agora dormimos um bocadinho, só. Vamos ficar no filme só a dormir. É um filme sobre duas pessoas a dormir. Já fizeram isso. Não era original”. Essa cena celebra a singularidade desse "aqui e agora" que aquelas duas pessoas - 
pessoas ou personagens que conseguem encarnar as ideias de neta e avó, indo portanto para lá delas mesmas - põem em representação. Isto por muito que um Andy Warhol tenha inventado o dispositivo, e este tenha sido copiado mil vezes.

Esta não é a única vez que o filme internaliza o seu próprio "discurso", revelando a sua construção simultaneamente pessoal e teórica, a sua dimensão de filme-diário (fluxos do "eu") e de filme-tese (composição ou inscrição de uma certa "técnica fílmica"). Com efeito, um dos temas de Gipsofila é o seu próprio processo. Margarida Leitão disse-me em entrevista que este foi um filme feito sem grande preparação, um exercício "no vazio", sem medo do passado e do futuro. Atirado, portanto, para as possibilidades de um presente que se desenrola à frente da câmara. A propósito destas bem-vindas "crises existenciais" do e no filme, lembrei-me de dois aforismos de Paul Valéry (2007: 205): "O passado está entre o presente e o futuro - é a primeira consequência - e o futuro, a segunda", donde "Perder a vida [é] perder o futuro./ - Não és o futuro de todas as recordações que estão em ti? O futuro de um passado?". A avó ensina a neta a não ter pressa de ter passado e de ter futuro - de ter o "futuro de um passado" -, isto é, oferece a esta o segredo que a idade, na sua sabedoria própria, lhe revelou, a de que a felicidade se surpreende nos pequenos nadas do momento presente. É o "ir vivendo" a grande lição que uma avó pode dar a uma neta ou a um neto. $\mathrm{O}$ filme acaba por ser mais sobre esta temporalidade transformada, pelo instante tocado pela vida e pela morte (pelo amor), do que sobre a relação de Margarida Leitão com a sua avó Lourdes Albuquerque.

Paradoxalmente, a imprecisão ou, para usar a noção de Umberto Eco $(2009,227)$, a "abertura" de Gipsofila é a principal fonte da sua precisão formal, na medida em que este projeto nasce de uma ciência, a ciência de que o cinema pode/deve ser como a vida e fazer-se como se pouco ou nada se soubesse sobre ele. Por isso, deve realizar-se em absoluta cumplicidade com o "imediato" da vida. Neste sentido, há nele qualquer coisa de "televisivo", se soubermos extrair desse conceito - como o fez André Bazin (2014: 122) antes de toda a gente - a sua intrínseca dimensão metafísica. A "decidida indecisão" - que chamaria de "indecisão teórica" - quanto ao que é, de onde veio e para onde vai, é fermentada, desde logo, na situação da "protagonista", a própria Margarida Leitão, que atravessa uma crise existencial à porta dos quarenta anos, e da avó, que ouve o chamamento do seu anjo da guarda. O filme é o processo de ocupação deste tempo de impasses, dúvidas e "pequenos nadas".

Apesar disso ou por causa disso, vários são os momentos em que Gipsofila dobra sobre si mesmo, como que colocando a nu as suas próprias costuras; como se aqui o principal tema fosse mais a enunciação do que o enunciado, 
o "como se faz" vis-à-vis "como se vive" muitas vezes antes de "o que se faz" vis-à-vis "o que se vive". A avó defende a naturalidade interpretativa nos filmes e novelas; fala sobre o facto de a vida ser feita de pequenos nadas e, como já vimos, questiona a neta sobre a relevância de a filmar enquanto dorme. Todas estas "cenas", "episódios" ou "blocos de tempo" problematizam muito diretamente o filme em si mesmo. De facto, Margarida Leitão não esconde a câmara do seu "modelo". Muito pelo contrário: ela envolve-o, engaja-o, apetece dizer, em todo o processo de filmagem.

Se há aqui linguagem do direto televisivo, esta é a de um direto expurgado de qualquer voyeurismo. Não se promove aqui qualquer intrusão no íntimo, há, antes, uma problematização constante - puramente teórica - dessa intrusão. A vida teoriza o cinema, o cinema teoriza a vida. Há uma prática reflexiva, constante, entre os dois. Tal como entre neta e avó se debatem questões de som e de imagem. "Vem, avó, ver a luz que reflete no Cristo", "Ouves, avó, o som do vento?". A neta faz reparar e repara, muito literalmente, os sons e imagens no filme. Ela conserta um gira-discos antigo, que não tocava há vinte anos, diz a avó, que logo depois confidencia: "Eu é só televisão, televisão, televisão. Porque assim não se vê. Na rádio não se vê". Ela conserta a televisão quando a avó já se mentalizava que seria preciso comprar outra.

Ela repara e faz reparar os sons e as imagens, mas a avó também faz $o$ seu cinema em Gipsofila. Ela mostra à neta as fotografias do velho álbum de fotografias. Aponta para cada fotografia, identificando e apreciando o que vê. Ela desenha as gipsófilas que semeou, regou e pôs em jarras para o seu casamento. Escreve "pelo som" na folha branca de um caderno - com isso, batiza o filme - e desenha a flor ao lado para ilustrar. Acima de tudo, a avó dirige a neta-realizadora. Dá-lhe indicações sobre onde pôr a câmara em função da luz do sol, por exemplo. Ela pronuncia-se sobre a imagem da neta quando esta lhe pede para verificar a sua figura no enquadramento. Ela dá o exemplo quando fala com vaidade da sua própria vaidade: "Arranjo-me sempre. Ainda hoje me arranjo para te receber". Para usar uma distinção cara a Mekas, se a neta é filmmaker, a avó é director.

Era Jacques Rivette (1958: 47) que dizia que a única crítica verdadeira a um filme era outro filme. Pois bem, a melhor crítica a Gipsofila é, ou melhor, está em Gipsofila. A sua direção - teórica, especulativa, "académica" - choca com o seu objeto - aberto, não-significante, imprevisível. É o objeto-tese a fazer "carga de ombro" ao objeto estético, imerso na sua duração de cinema como duração de vida. Pode-se escrever infinitamente sobre Gipsofila porque nele nada de definitivo se inscreve a não ser o seu propósito de fazer cinema na imanência da vida. Rigorosamente. 
A câmara pensante, pensada, de Leitão deve muito a Warhol, mas deve ainda mais a Chantal Akerman, nomeadamente aos seus filmes-laboratório onde o "eu" se revela debaixo de um regime de cativeiro tão físico quanto mental. De La chambre a No home movie. Aliás, que o filme de Margarida Leitão seja anterior ao derradeiro sopro de Akerman não torna este último menos urgente para a compreensão do gesto do primeiro, até porque de "home movie" o filme da portuguesa acaba, inevitavelmente, por ter pouco. Ao mesmo tempo, são dois filmes sobre coabitações violentas; fechamentos por onde o tempo passa. Claro que a violência é insuperavelmente superior no filme de Akerman, na sua desesperante impossibilidade de antecipar a morte, que vai desembocar num último plano que é, na realidade, um plano último; um fora de campo que é uma forma de violento autoextermínio (supressão irreversível do "eu" que filma).

Leitão não atravessa exatamente as mesmas divisões (internas e externas) de Akerman. Apesar de Gipsofila ser um filme sobre a morte - outrossim cheio de "tempos mortos" -, todo ele está pontuado pela vida - a começar pelos seus jogos discursivos, o seu brilhante "desafio de tese" - e tudo nele é superável, ao passo que No home movie é um filme-apocalipse onde nada redime nada, como se nele o mundo não tivesse janelas. Veja-se como a dor na neta, provocada pelas palavras da avó acerca do medo que tem de morrer, é almofadada por uma frase inútil dita entre lágrimas, que na sua insignificância a - e nos - faz "seguir vivendo": "Acho normal... Faz parte da vida, não é?"

\section{Referências bibliográficas}

Bazin, A. (1992). O que é o Cinema?. Lisboa: Livros Horizonte [1958].

Bazin, A. (2014). André Bazin's New Media. Editado e Traduzido por Dudley Andrew, Oakland: University of California Press.

Eco, U. (2009). Obra Aberta. Lisboa: Difel [1962].

Mekas, J. (1960). Cinema of the New Generation. Film Culture 21, Ve-rão: $1-20$.

Rivette, J. (1958). L'âme au Ventre (Sommarlek, Ingmar Bergman). Cahiers du Cinéma, Junho: 45-47.

Tyler, P. (1995). Underground Film: A Critical History. Introdução por J. Hoberman e Posfácio por Charles Boultenhouse. Nova Iorque: Da Capo Press [1969].

Valéry, P. (2007). Cuadernos (1894-1945). Barcelona: Galáxia Gutenberg/ Círculo de Lectores. 